\title{
Axiomatic decomposition of a zero-sum game: the penalty shoot-out case
}

\author{
Fernando Rolli ${ }^{1 *}$, , João Fradinho ${ }^{2}$, Alessandro Giorgetti ${ }^{1}$, Paolo Citti $^{1}$ and Gabriele Arcidiacono ${ }^{1}$ \\ ${ }^{1}$ Department of Innovation and Information Engineering, Guglielmo Marconi University, Via Plinio 44 - 00193 Rome, Italy \\ ${ }^{2}$ UNIDEMI \& DEMI, Faculdade de Ciências e Tecnologia, Universidade Nova de Lisboa, Campus de Caparica, Caparica \\ 2829-516, Portugal
}

\begin{abstract}
The game of soccer has offered matter of wide scientific analysis about the effective application of the game theory in real-life. The field observations have often detected divergent behaviors from theoretical predictions. The basic problem comes from the fact that it is difficult to build scientific models reflecting reality as closely as possible. Axiomatic Design offers us a powerful tool of rational decomposition of a real and complex issue into elementary components. Independence Axiom guarantees that game decomposition will define a set of elementary actions logically consistent and free of redundancies. At the same time, Information Axiom can allow to select among alternative strategies, those that they predict the actions with a higher probability rate of success. In this paper, it is suggested the use of the Axiomatic Design methodology in the Collectively Exhaustive and Mutually Exclusive (CEME) mode, as a tool of analysis of the penalty shoot-out in extra time. This methodology allows to define the game strategies for goalkeepers and penalty takers. It will be analyzed both, the case when the opponents' behavior is well known and the situation when the statistics about the opponents are unknown. Axiomatic Design allows the process of decomposition to be simplified, enabling the selection of optimal game strategies. These strategies correspond to Nash's equilibrium solutions when you already know about your opponents' game behavior. On the contrary, when penalty takers whose behavior is unknown, then it is always possible to define a strategy corresponding to the Bayesian equilibrium game solutions.
\end{abstract}

\section{Introduction}

The game of soccer is the most popular sport in the world. It feeds an economic business of considerable proportions. In Italy, it represents an important economic sector in terms of business compared to the PIL [1]. The only lack of participation of the Italian national soccer team to the 2018 World Cup Russia, has been estimated as a direct loss of the state system amounting to EUR 100 million, without considering the income it would have been generated. At the same time, the game of soccer represents a useful workshop to ascertain the extent of the game theory. It has a very wide application in both finance and social science. In this paper, it is presented a case of functional decomposition application of the Collectively Exhaustive and Mutually Exclusive (CEME) methodology, already studied by authors in different areas $[2,3]$ so to define a process of drawing up of robust strategies for penalty shootouts. The penalty shootouts are used in play-offs, in case after extra time the two opposing teams are still in draw. They are constituted by five penalty shootouts the two teams kick alternately to decide the winning team of the match. Unfortunately, this kind of game cannot be formulated as a repeated one. The couple goalkeeper-kicker changes at every turn. Thus, the game agents are the two goalkeepers and at least ten kickers. The complexity of the game rises the necessity to identify a very affordable methodology of decomposition. Such a tool must allow to decompose a complex system in a sum of elementary games, preserving at the same time the intrinsic features of the primary game. For this reason, we propose the approach of the so-called Collectively Exhaustive and Mutually Exclusive (CEME) methodology [4, 5]. It allows to decompose in an affordable way this set of penalty shootouts alternately per team. They are elementary penalty shootouts, separately assessed. A complex situation can be organically modelled as a sum of elementary games in this way. AD also allows to selectively identify the critical situations diverting the real case from the theoretical model.

\subsection{Big data and soccer}

The building of a forecast model is the provision of accurate information about kickers, matches and tournaments. Compared to other American sports having a long history in the use of statistics, soccer has only shown an interest in this respect in the last few years [1]. There are several consulting firms providing accurate information on the market. Professional sport clubs widely rely on these consultancies. Big data analyses are used in the transfer market not only for the aim of recruiting soccer players to pick, but also to set valid game strategies, when you face up to specific opponents.

Corresponding author: f.rolli@unimarconi.it 


\subsubsection{Axiomatic decomposition of the game actions}

In the era of digital communication, the information is readily available. Unfortunately, this information is to be interpreted and duly tied up by each single team. Every technical staff has his own way to use such information. They range from conventional approaches based on coach's personal experience, to more structured ones, such as in American sports. In these latter cases, the building of a strategy is defined by rational rules of game actions decomposition. In this paper, we will focus on the CEME axiomatic methodology so to decompose a set of extra time penalty shootouts into elementary actions, by which you can define winning strategies.

\subsubsection{Building of a structured DataBase}

$\mathrm{AD}$ decomposition methodology of game actions defines winning strategies on elementary basis actions. Such decomposition is aimed at the matches already played and the upcoming matches against the next opponents. Thus, building a structured DataBase is equivalent to digitize the activities of the technical area of a soccer team. Such a tool can be implemented as a multilevel database on HNCR (Holistic non-Conformity Reduction) based approach [6-10]. These types of DataBase make it possible to record soccer players' individual actions through the allocation of structured and unique elementary data. This can proactively identify the strengths or weaknesses of the opposing teams, by making analytical insights having an impact on the soccer player in the game dynamics. It is to exploit the experiences gained over the years with a lesson learned that can help us to define the game plans and the specific interpretations made by the examined soccer players. Such an abstraction allows us to put in place preventive game plans, specific for each opponent. One can set up in a more rational way, avoiding being caught from a tactical perspective. Moreover, the system must allow the cataloguing and registration of soccer players' technical data including their mental and physical condition.

\section{The penalty shoot-out in the game theory}

The penalty shoot-out is a classic example of noncooperative game between two zero-sum agents [11]. This means that kicker and goalkeeper do not cooperate with each other, but each of the two players pursues divergent objectives. Kicker's gain represents goalkeeper's loss and vice versa.

\subsection{Premise}

The rules of the game are very clear. The kicker places the ball on a stationary point in the penalty area which is 11 feet from the goal line. The goal door is 2,44 feet high and 7,32 feet wide. The goalkeeper stands still in the centre of the goal door. The kicker can in a simplified manner kick right, left or centre (R, L, C). Similarly, as for the kicker there is only three strategies a goalkeeper has, diving to the left, right or stand in the centre $(\mathrm{R}, \mathrm{L}$, C) [12]. For the sake of simplicity, we always mention the goalkeeper as a reference. Therefore, kicking leftside always means kicking to the goalkeeper left-side. The ball takes about 0.3 seconds to hit the back of the net. That means the goalkeeper cannot decide which strategy adopting after the player has kicked, because afterwards it will be too late. For this reason, both goalkeeper and kicker's strategies are independent. In this paper, the outline of a penalty kick, as defined by Chiappori et alii [13], acts as a model. Based on this model the penalty shoot-out can be represented by the matrix of Table 1. It is assumed that the kicker always hit the target.

Table 1. Payoff matrix

\begin{tabular}{|c|c|c|c|}
\hline \multicolumn{5}{|c|}{ Goalkeeper } \\
\hline Kicker & $\mathbf{L}$ & $\mathbf{C}$ & $\mathbf{R}$ \\
\hline $\mathbf{L}$ & $\mathbf{P}_{\mathrm{L}}$ & $\boldsymbol{\pi}_{\mathbf{L}}$ & $\boldsymbol{\pi}_{\mathbf{L}}$ \\
\hline $\mathbf{C}$ & $\boldsymbol{\pi}$ & $\mathbf{0}$ & $\boldsymbol{\pi}$ \\
\hline $\mathbf{R}$ & $\boldsymbol{\pi}_{\mathbf{R}}$ & $\boldsymbol{\pi}_{\mathbf{R}}$ & $\mathbf{P}_{\mathrm{R}}$ \\
\hline
\end{tabular}

$\mathrm{P}_{\mathrm{L}}$ is the probability that the kicker might score, by kicking left, while the goalkeeper is diving in the same direction;

$\pi_{\mathrm{L}}$ is the probability that the kicker might score, by kicking left, while the goalkeeper stands still in the centre or dives to the right;

$\pi$ is the probability that the kicker might score, by kicking centre, while the goalkeeper dives to the kicker's left or right;

$\pi_{\mathrm{R}}$ is the probability that the kicker might score, by kicking right, while the goalkeeper dives in the opposite direction or stands in the centre;

$\mathrm{P}_{\mathrm{R}}$ is the probability that the kicker might score, by kicking right, while the goalkeeper dives in the same direction.

Mixed strategy is the game where at each single action of the kicker (L, C, R), does not correspond a certain (deterministic) action of the goalkeeper. This depends on the perfect coincidence in time of both goalkeeper and kicker's actions. Therefore, mixed strategies shall consist of a probability distribution among several possible strategies $\left(\mathrm{P}_{\mathrm{L}}, \pi_{\mathrm{L}}, \pi, 0, \pi_{\mathrm{R}}, \mathrm{P}_{\mathrm{R}}\right)[12,13]$.

\subsection{Equilibrium conditions}

The game is in equilibrium when all players have adopted a well combination of those strategies that none of them could be able to gain by changing their own strategy. The minimax (or maximin) theorem states that every game ended up in a constant sum between two agents, holds at least a minimax equilibrium point in pure or mixed strategies [13]. This means that each game 
ended up constant sum, admits a winning strategy. The existence of an equilibrium condition of this type would be true also for a generic game with $n$ players. This result derives from Nash's theorem [14]. We can consider this last theorem as the generalisation of a $n$ player in the minimax theorem [13]. In the specific case of the penalty shoot-out, the consequences of the minimax theorem (this is equivalent to the 2-players Nash's theorem) are the following [12]:

1. Each player has the same probability of success in case he has chosen one of the three possible strategies (L, C, R);

2. Each single player's choices must be independent. There cannot be any relationship with other choices made earlier.

This means that the minimax equilibrium condition (Nash's equivalent) consists of carrying out a completely random strategy [11-13].

\subsection{Typologies of equilibrium}

The game model proposed by Chiappori et alii [13] considers that soccer players may choose two different shooting techniques.

\subsubsection{Restricted randomization equilibrium}

Some kickers have a strong preference to kick penalty shootouts exclusively to the right or to the left of the opposing goalkeeper, avoiding shooting to the centre of the goal door. This case is about restricted randomization equilibrium (RR). It is characterized by very small values of $\pi$, meaning that the probability of the player shooting to the centre is zero or negligibly small. In this case, Nash's equilibrium condition reflects the fact that the player has the same probability of success kicking right or left.

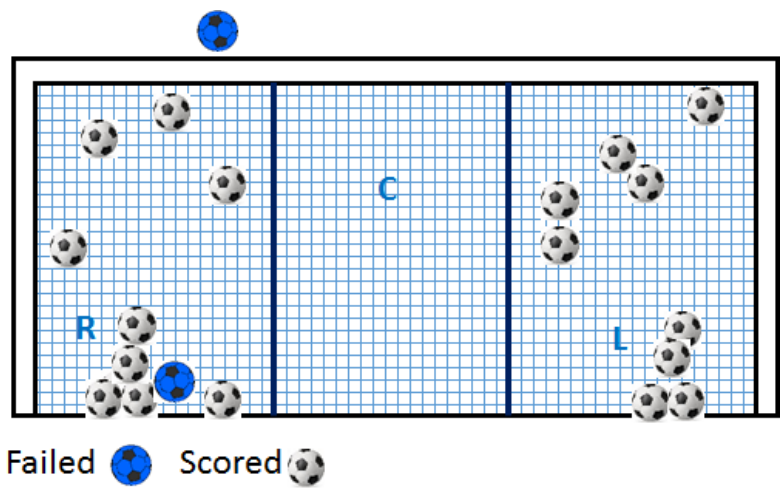

Fig. 1. Arturo Vidal's penalty shoot-out behavior. Source: The Wall Street Journal (2014)

\subsubsection{General randomization equilibrium}

Other players kick penalty shootouts in the three directions interchangeably. In this case is about randomization equilibrium (GR) and Nash's equilibrium condition corresponds to the fact that the player has the same probability of success to kick to the goalkeeper's right, centre or left.

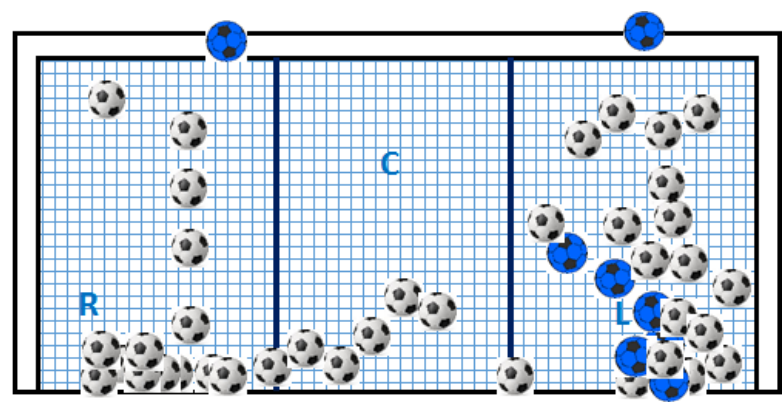

Failed Scored

Fig. 2. Lionel Messi's penalty shoot-out behavior. Source: The Wall Street Journal (2014)

\section{Interpretation of the penalty shoot-out in terms of $A D$}

Penalty shoot-out decomposition into elementary strategies can occur in terms of Axiomatic Design according to two different but complementary points of view. We can consider kicker's perspective who wants to maximize his gain by scoring a goal. We can also side with the goalkeeper in the same way to minimise kicker's actions. Both players strategies are independent. They may be represented as two autonomous and complementary decompositions. Naturally, both decompositions are self-consistent, while representing two different perspectives. In the interests of simplification we consider only those players having a GR-type shooting behavior so far.

\subsection{Penalty taker strategies in general randomization equilibrium (GR)}

First up the application of the CEME methodology from the more general situation of the penalty shootouts (GR). The penalty taker kicks indifferently left, right or centre of the goal door. His only aim in front of the goalkeeper is to score the goal. In this case the functional requirement of more abstract level (FRa0) is: Maximize penalty shoot-out. Such a functional requirement can be met through kicker's strategy (DPa). At this point, we can decompose FRa0 into three functional requirements of inferior level:

- Score goal on goalkeeper's left-side (FRa1);

- Score goal in the centre (FRa2);

- Score goal on the right (FRa3).

These three functional requirements can be met in an exclusive manner from the following three strategies:

- Kick on goalkeeper's left (DPa1);

- Kick in the centre of the goal door (DPa2);

- Kick on the left (DPa3).

Based on this model the penalty taker strategies can be represented by the matrix of Table 2 . 
Table 2. Penalty taker strategies in general randomization equilibrium

\begin{tabular}{|c|c|c|c|c|}
\hline \multicolumn{5}{|c|}{ General randomization equilibrium } \\
\hline & $\begin{array}{c}\text { Possible } \\
\text { strategies }\end{array}$ & $\begin{array}{c}\text { Penalty } \\
\text { taker kicks } \\
\text { left }\end{array}$ & $\begin{array}{l}\text { Penalty taker } \\
\text { kicks centre }\end{array}$ & $\begin{array}{l}\text { Penalty } \\
\text { taker kicks } \\
\text { right }\end{array}$ \\
\hline \multirow{3}{*}{ 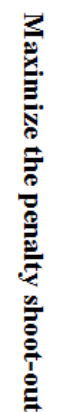 } & $\begin{array}{c}\text { Score a } \\
\text { goal on the } \\
\text { left }\end{array}$ & $\boldsymbol{a}_{11}$ & & \\
\hline & $\begin{array}{c}\text { Score a } \\
\text { goal in the } \\
\text { centre }\end{array}$ & & $\boldsymbol{a}_{22}$ & \\
\hline & $\begin{array}{c}\text { Score a } \\
\text { goal on the } \\
\text { right }\end{array}$ & & & $\boldsymbol{a}_{33}$ \\
\hline
\end{tabular}

We will be able to carry on our analysis to a more elementary level by introducing a successive decomposition. We could split the three detected shooting areas into three next sub-areas: low, medium and high. Such sectors would correspond to the level, medium and high-shots. By the way, for our essay this is not relevant.

\subsection{Predicting goal-scoring in Nash's equilibrium}

The three strategies referred to in the previous paragraph are Collectively Exhaustive and Mutually Exclusive (CEME). This guarantees the Independence Axiom is met. Furthermore, through Table 1 it is possible to measure each single scoring modality. Let us indicate with $\mathrm{a}_{11}$ the probability to score a goal left. Similarly, $\mathrm{a}_{22}$ is the probability to score a goal in the centre, while $\mathrm{a}_{33}$ is the probability to score a goal right. Let us consider $\mathrm{g}_{\mathrm{L}}$ as the goalkeeper's probability to dive to the left, and $\mathrm{g}_{\mathrm{C}}$ as the goalkeeper's probability to stand still in the centre. This way, goalkeeper's probability to dive himself to his right will be $1-g_{L}-g_{C}$. Considering values in Table 1 there will be $[12,13]$ :

$\mathrm{a}_{11}=\mathrm{g}_{\mathrm{L}} \mathrm{P}_{\mathrm{L}}+\mathrm{g}_{\mathrm{C}} \pi_{\mathrm{L}}+\pi_{\mathrm{L}}\left(1-\mathrm{g}_{\mathrm{L}}-\mathrm{g}_{\mathrm{C}}\right)=\mathrm{g}_{\mathrm{L}} \mathrm{P}_{\mathrm{L}}+\pi_{\mathrm{L}}\left(1-\mathrm{g}_{\mathrm{L}}\right)(1) ;$

$\mathrm{a}_{22}=\mathrm{g}_{\mathrm{L}} \pi+\mathrm{g}_{\mathrm{C}} 0+\pi\left(1-\mathrm{g}_{\mathrm{L}}-\mathrm{g}_{\mathrm{C}}\right)=\pi\left(1-\mathrm{g}_{\mathrm{C}}\right)(2)$;

$a_{33}=g_{L} \pi_{L}+g_{C} \pi_{R}+P_{R}\left(1-g_{L}-g_{C}\right)(3)$.

\subsection{Goalkeeper strategies in general randomization equilibrium (GR)}

Goalkeeper's duty is neutralizing the penalty shoot-out. In this case the functional requirement of more abstract level $\left(\mathrm{FR}_{\mathrm{b} 0}\right)$ is: Minimize the penalty shoot-out. Such functional requirement can be met through goalkeeper's strategy $\left(\mathrm{DP}_{\mathrm{b} 0}\right)$. At this point, we can decompose $\mathrm{FR}_{\mathrm{b} 0}$ into three lower level functional requirements: Catch left $\left(\mathrm{FR}_{\mathrm{b} 1}\right)$, Catch centre $\left(\mathrm{FR}_{\mathrm{b} 2}\right)$ and Catch right $\left(\mathrm{FR}_{\mathrm{b} 3}\right)$. These three functional requirements may be exclusively met by the following three strategies: Goalkeeper dives to the left $\left(\mathrm{DP}_{\mathrm{b} 1}\right)$, Goalkeeper stands still in the centre $\left(\mathrm{DP}_{\mathrm{b} 2}\right)$,
Goalkeeper dives to the right $\left(\mathrm{DP}_{\mathrm{b} 3}\right)$. Based on this model the goalkeeper strategies can be represented by the matrix of Table 3. However, similarly as described in paragraph 3.1, Table 1 allows each catching technique to be measured.

Table 3. Goalkeeper strategies in general randomization equilibrium

\begin{tabular}{|c|c|c|c|c|}
\hline \multicolumn{5}{|c|}{ General randomization equilibrium } \\
\hline & $\begin{array}{c}\text { Possible } \\
\text { strategies }\end{array}$ & $\begin{array}{c}\text { Goalkeeper } \\
\text { dives to the } \\
\text { left }\end{array}$ & $\begin{array}{l}\text { Goalkeeper } \\
\text { stands still in } \\
\text { the centre }\end{array}$ & $\begin{array}{l}\text { Goalkeeper } \\
\text { dives to the } \\
\text { right }\end{array}$ \\
\hline \multirow{3}{*}{ 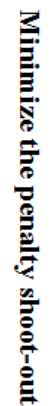 } & Catch left & $\mathbf{b}_{11}$ & & \\
\hline & $\begin{array}{l}\text { Catch } \\
\text { centre }\end{array}$ & & $\mathbf{b}_{22}$ & \\
\hline & Catch right & & & $\mathbf{b}_{33}$ \\
\hline
\end{tabular}

\subsection{Considerations around the Information Axiom}

The application of Information Axiom leads us to a very active subject in game theory. In case of a pure and zerosum game strategy, the Information Axiom would lead us selecting a robust solution. That solution would have corresponded to the equilibrium point of the minimax theorem for that game. Unfortunately, the penalty shootout is a zero-sum game but with a mixed strategy. The most valid game behavior is the random one for which all available strategies are valid [11-13]. So, this means that, a robust strategy does not exist, but an equilibrium situation that meets the Minimax theorem does. In other words, it has been shown that in volume and for professional soccer players, the averages of $\left(\mathrm{P}_{\mathrm{L}}, \pi_{\mathrm{L}}, \pi, 0\right.$, $\left.\pi_{R}, P_{R}\right)$ tend to converge towards fixed and steady values $[12,13,15]$. This means that in general randomization equilibrium conditions, the result is $\mathrm{a}_{11}=\mathrm{a}_{22}=\mathrm{a}_{33}$. However, in conditions of restricted randomization the result is $a_{11}=a_{33}$ with $a_{22}=0$. On the contrary, goalkeepers have a constant behavior [13]. For this reason, in Nash's equilibrium conditions the result is $b_{11}=b_{22}=b_{33}$. On the contrary, in situations of relevant physical and mental stress each single player can have significant deviations from the medium values foreseen by the minimax theorem [12, 16]. Palacios Huerta [12] stated that, on a sample of 1417 penalty shootout kicked in the period September 1995 - June 2000 in the most important European championships, the scoring probability decreases as the game time increases. This means that kicker's behavior has the tendency to diverge from the standard model foreseen by the minimax theorem when some stress prevails. 


\begin{tabular}{|l|c|c|c|c|c|c|c|c|c|c|}
\hline & LL & LC & LR & CL & CC & CR & RL & RC & RR & All penalties \\
\hline Scored penalties & 16 & 2 & 17 & 10 & 0 & 9 & 12 & 6 & 7 & 79 \\
\hline Failed penalties & 13 & 0 & 0 & 1 & 0 & 0 & 1 & 0 & 8 & 23 \\
\hline All penalties & 29 & 2 & 17 & 11 & 0 & 9 & 13 & 6 & 15 & 102 \\
\hline $\begin{array}{l}\text { Scoring rate } \\
\text { Lionel Messi }\end{array}$ & $55,17 \%$ & $100 \%$ & $100 \%$ & $90,91 \%$ & $0 \%$ & $100 \%$ & $92,31 \%$ & $100 \%$ & $46,67 \%$ & $77,45 \%$ \\
\hline
\end{tabular}

Table 4. Lionel Messi's penalty shoot-out distribution

In these conditions, soccer players are lead to kick badly or being much more predictable by goalkeeper. During penalty shootouts in extra time such deviation is often even more marked. Thus, it often occurs that top players, used to kick penalty shootouts, fail them in these very particular situations. So, physical and mental stress induces soccer players to leave the standard random model towards specific behavior preferences $[12,16]$. In other words, such that $a_{11} \neq a_{22} \neq a_{33}$ (similarly for the goalkeeper such that $b_{11} \neq b_{22} \neq b_{33}$ ). Later, in our essay, we will see what, despite everything, even with these deviations, we can build a useful forecasting model so to define a winning strategy in case of penalty shootouts in extra time.

\subsection{How Hannes Halldorsson succeeded in catching Lionel Messi's penalty shoot-out}

The recent 2018 World Cup Russia can be used as a lab for penalty shootouts. As such, it is a basis for studying mathematical models of real situations. Let us take as a case study the Argentinian champion Lionel Messi's shoot-out which has been so ably caught by the Icelandic goalkeeper Halldorsson. Lionel Messi has been the greatest soccer player, together with Cristiano Ronaldo for a decade. Messi has all the qualities to be considered as an ideal penalty kicker from a mathematical point of view. He is a very precise and strong left-footed player.

He has a fierce concentration and when kicking a shootout, he does not pay any attention both to the stadium crowd and to the opponent goalkeeper smirks. He looks deep in thought. We will notice, however that he does not have a high scoring average. In situations of relevant physical and mental stress he tends to have a scoring behavior in favour of Nash non-equilibrium solutions.

\subsubsection{Lionel Messi's real shooting behavior in penalty shootouts}

The website https://www.transfermarkt.com quotes 102 penalty shootouts kicked by Messi in official matches. The observation period goes from 2005 to the recent 2018 FIFA World Cup in Russia. Such a statistic basically includes almost the whole period where the Argentine soccer champion played like a pro. Every single shootout has been re-analyzed thanks to the videos available on the net. Observations were used as means of data collection. Data have been reported in Table 4 according to the approach followed by Palacios-Huerta [12]. Instead, referring to the already mentioned model by Chiappori et alii [13], we could make out 9 shooting strategies, as illustrated in Table 1. For example, by the abbreviation LL (Left-Left) we represent the shooting situation to goalkeeper's left who jumps in turn to his left. On the contrary, the abbreviation RL (Right-Left) indicates the shooting situation to goalkeeper's right who jumps in turn to the opposite side. Thus, the first letter means the shooting side of the penalty taker and the second one means the goalkeeper diving direction (LLeft, C-Center, R-Right). As for Lionel Messi there is a distribution of shootouts in official matches as stated in Table 4. Apart from the shooting strategy the table also shows if the shootout has been successful.

\subsubsection{Empirical analysis of Lionel Messi's shooting strategies}

Table 4 data suggests us that Messi tends to fail shootouts when kicking to the opponent goalkeeper 's right instead of the opposite direction. If, in addition, we use Figure 2, we can observe that the distribution shootouts kicked by Messi until 2014 is not completely standard on the whole door surface. Thus, we can glimpse some shooting strategies:

- S1. First shooting choice is represented by the opponent goalkeeper's left-side. This behavior is normal, since for a left-footed kicker comes easier kicking to the goalkeeper 's left side.

- S2. If you still observe Figure 2 you might notice that, when Messi kicks to the goalkeeper's right, he prefers kicking towards a very narrow door zone, halfway between the door center and the right goalpost. It is a door area where the goalkeeper can catch easier.

In these two areas is concentrated the almost total failed shootouts by Messi (Fig. 3).

\subsubsection{Axiomatic interpretation of a failed shoot-out}

From a theoretical point of view, Messi kicks his shootouts using the GR model. Thus, in Nash equilibrium conditions, in other words, in normal physical and mental conditions he can kick right, left or centre confounding the goalkeeper. However, the peculiar distribution of failed shootouts in the two above mentioned favorite areas will suggest us something else. Probably, Messi's shooting behavior goes from a General Randomization Equilibrium (GR)-type to a Restricted Randomization (RR without equilibrium) in conditions of physical and mental stress. Thus, in this new configuration the result is that $a_{11}>a_{33}$, on the 
contrary $\mathrm{a}_{22}=0$. This means that the probability to score a goal on the goalkeeper's left side is higher than scoring a goal on the opposite side. Indeed, the fact that the second preference area (S2) is pretty narrow and easily reachable by the goalkeeper increases Messi's probability to fail a shootout kicked to his right side. Such behavior is more visible in Messi's shootouts kicked after 2014. Hannes Halldorsson has chosen the best strategy with the higher rate of success after all, by diving to his right side towards S2 area. Fortune gave him a great reward. Halldorsson has adopted a pure strategy. $\mathrm{He}$ is a professional filmmaker. Probably, before the game he will have seen many movies on the penalties taken by Messi. Instead, Lionel Messi disregarded the characteristics of the Icelandic goalkeeper. He adopted a mixed strategy, deciding the side of the shot at the time of the penalty kick. Perhaps, the psychological tension of the moment led him to adopt a solution that conforms to a RR without equilibrium behavior. Most likely, also the chaos in the Argentine team at the recent 2018 FIFA World Cup Russia charged Lionel Messi of excessive responsibilities. Such a situation might have had a heavy psychic burden and have contributed to redirect Messi's shooting behavior from a General Randomization Equilibrium-type (GR) to a Restricted Randomization without equilibrium one ( $R R$ without equilibrium).

\subsubsection{Numerical verification of hypothesis of deviation from Messi's shooting behavior to Restricted Randomization without equilibrium}

Starting from the premises of the previous paragraph, we can verify if the hypothesis of deviation from Messi's shooting behavior from GR to RR without equilibrium is also supported by numerical data. Such verification is possible by using equations 1,2 and 3 described in $\S 3.2$ and by data gathered in table 4 RR without equilibrium condition means the same as:

- Messi can kick to goalkeeper's right or left-side only. In other words, this means that: $\mathrm{g}_{\mathrm{C}}=0$ and $\pi=0$;

- Probability to score goalkeeper's left-side differs from the one to score to his right. This means that the result is: $\mathrm{a}_{11} \neq \mathrm{a}_{33}$.

Furthermore, using test data produced by Palacios Huerta [12] we can put $g_{L}=0,4231$ where $g_{L}$ represents goalkeeper's probability to dive to the left. Instead, from Table 4 data we can set:

- $\mathrm{P}_{\mathrm{R}}=\mathrm{RR}($ Scoring rate Messi $)=0,4667$;

- $\mathrm{P}_{\mathrm{L}}=\mathrm{LL}($ Scoring rate Messi) $=0,5517$;

- $\pi_{\mathrm{L}}=\mathrm{LR}($ Scoring rate Messi) $=1$.

Under these conditions equations 1,2 and 3 at $\S 3.2$ become:

1. $\mathrm{a}_{11}=(0,4231 * 0,5517)+(0,5769 * 1)=0,81032$;

2. $\mathrm{a}_{22}=0$;

3. $\mathrm{a}_{33}=0,4231 * 1+(0,4667 * 0,5769)=0,69234$.

That would mean that $\mathrm{a}_{11}>\mathrm{a}_{33}$

Thus, numerical data coming from the 102 shootouts' observation kicked by Lionel Messi (Fig.3) confirm the hypothesis of deviation from Messi's shooting behavior from GR to RR without equilibrium due to physical and mental stress. However, this hypothesis is a simple abstraction based primarily on a visual observation of the areas of Messi's shooting preferences (Fig.2). In this paragraph we have only verified that the proposed model is logically consistent with the numerical data of Table 4. This does not mean that it can completely and definitively define the player's behavior. Messi could also change shooting behavior. Therefore, this model can be understood only as an attempt to simplify the representation of a very complex behavior.

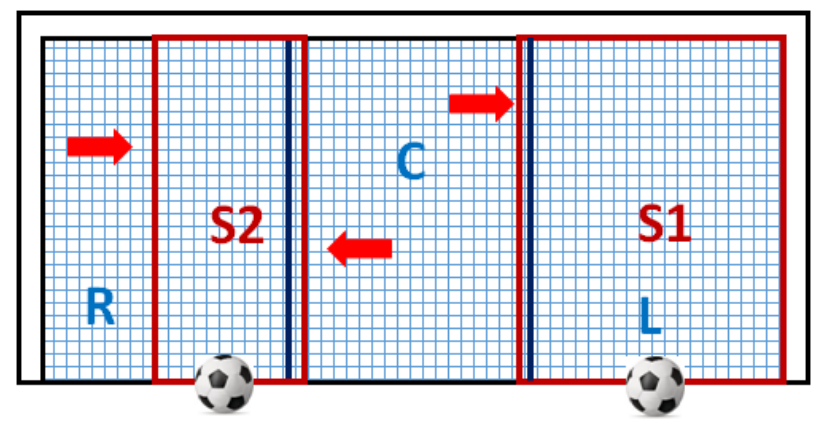

Fig. 3. Graphical representation of Lionel Messi's shooting areas under stress conditions (S1, P2)

\section{AD CEME methodology application to the penalty shootouts in ideal conditions}

The aim of each soccer team is scoring at least one additional goal than his opposing team. This objective is the first level functional requirement (FR0). Thus, each team seeks to maximize his own gain. This would mean scoring as many goals as possible. Equivalently, the same team tries to minimize his own loss. This would mean to adopt a strategy which allows his own goalkeeper to catch as many opposing kicker's shootouts as possible. This work uses the CEME methodology based on the functional metrics (FMs) and the parentchild equations for guiding the decomposition of a design for winning games [4, 5]. The hypothesis is that controlling appropriate FMs can increase the likelihood that a team can outscore their opponent [4].

\subsection{Decomposition methodology}

The penalty shootouts sequence in extra time consists of a series of simple and linear actions. In theoretical and ideal conditions there is no correlation among subsequent actions. In such conditions, every event is independent from the previous ones. These features allow to schematize the entire process through the building of a theoretical model, for which each single action is axiomatically independent from the previous one. Such hypothesis let us easily decompose the entire process into elementary actions in accordance with the AD methodology CEME-type. Every elementary action can be easily traced back to the penalty shoot-out case already dealt with in $\S 3$. 


\subsubsection{First level decomposition}

At this point, first level functional requirement $\left(\mathrm{FR}_{0}\right)$ can be likely decomposed into two second level functional requirements, in accordance with the $\mathrm{AD}$ methodology with CEME approach $[2,3]$.

- $\mathrm{FM}_{0}:-$ Score $=\Sigma($ Scored shootouts $)-\Sigma($ Scored

shootouts by opponents) -;

- $\mathrm{FR}_{0}$ : - Maximize score -;

- DP0: - Game strategy -;

- $\mathrm{FM}_{1}:-\Sigma($ Scored shootouts $)=\Sigma($ Kicked shootouts $)-$

$\Sigma$ (Failed shootouts) -;

- $\mathrm{FR}_{1}$ : - Maximize $\Sigma$ (Scored shootouts $)=$ Minimize $\Sigma$

(Failed shootouts) -;

- $\mathrm{DP}_{1}$ : - Kickers strategy -;

- $\mathrm{FM}_{2}:-\Sigma$ (Scored shootouts by opponents $)=\Sigma$

(Shootouts kicked by opponents) $-\Sigma$ (Failed shootouts by opponents) -;

- $\mathrm{FR}_{2}$ : - Minimize $\Sigma$ (Scored shootouts by opponents $)=$

Maximize $\Sigma$ (Failed shootouts by opponents) -;

- $\mathrm{DP}_{2}$ : - Goalkeeper strategy -.

\subsubsection{Methodological considerations}

The two derived functional requirements $\left(\mathrm{FR}_{1}\right)$ e $\left(\mathrm{FR}_{2}\right)$ are collectively exhaustive because they include all $\mathrm{FR}_{0}$ specifications. Furthermore, the same requirements are also mutually foreclosing as they do not have any element in common. Table 5 also shows that the Independent Axiom is met. However, the the greatest theoretical contribution of the proposed approach is representing a MiniMax problem through a smooth CEME decomposition. This is possible due to the axiomatic nature of both methodologies. For this reason, it was decided to proceed to the game actions decomposition resorting to their own use terminologies in game theory, so to underline the equivalence at every level of the two approaches.

Table 5. First level decomposition of penalty shootouts

\begin{tabular}{|c|c|c|c|}
\hline & & \multicolumn{2}{|c|}{ Game strategy (DP0) } \\
\hline & & $\begin{array}{l}\text { Penalty takers } \\
\text { strategy (DP1) }\end{array}$ & $\begin{array}{l}\text { Goalkeeper } \\
\text { strategy (DP2) }\end{array}$ \\
\hline \multirow{2}{*}{ 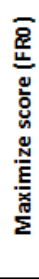 } & $\begin{array}{l}\text { Minimize } \Sigma \\
\text { (Failed } \\
\text { shootouts) (FR1) }\end{array}$ & $\mathbf{X}$ & \\
\hline & $\begin{array}{l}\text { Maximize } \Sigma \\
\text { (Failed } \\
\text { shootouts by } \\
\text { opponents) } \\
\text { (FR2) } \\
\end{array}$ & & $\mathbf{X}$ \\
\hline
\end{tabular}

\subsection{Second level decomposition}

FR1 can be decomposed into 5 penalty shootouts at the disposal of $\mathrm{X}$ team. To each penalty shoot-out we must associate an Xi kicker and the GY opposing goalkeeper. A specified shooting strategy will be linked to a penalty shoot-out. Every strategy depends on both $\mathrm{Xi}$ and GY features. Similarly, FR2 can be decomposed into 5 penalty shootouts kicked by the opposing team (Y). In this case $i$-th functional requirement consists of maximizing GX goalkeeper's action. He must try to let the opposing kickers (Yi) fail the penalty shoot-out. Both teams rotate in the penalty shootouts until both have kicked 5 each. However, if a team scored more shootouts than the other one and the latter is a tough act to follow, even scoring the remaining penalty shootouts, the match will end earlier. If, at the end of the ten penalty shootouts both teams have scored an equal number of goals, the match will go into sudden-death. It takes place then a shoot-out on each side until, after having kicked the same number of shootouts, a team will have an advantage over the other.

- $\mathrm{FM}_{1 \mathrm{i}}$ : - Pr (Fail i-th shoot-out by $\mathrm{X}_{\mathrm{i}}$ kicker) -;

- $\mathrm{FR}_{1 \mathrm{i}}$ : - Score a goal by $\mathrm{X}_{\mathrm{i}}$ kicker and GY goalkeeper -;

- $\mathrm{DP}_{1 \mathrm{i}}$ : - i-th shooting strategy by $\mathrm{X}_{\mathrm{i}}$ kicker -;

- $\mathrm{FM}_{2 \mathrm{i}}$ : - Pr (Catch i-th shoot-out to $\mathrm{Y}_{\mathrm{i}}$ kicker) -;

- $\mathrm{FR}_{21}$ : - Catch i-th penalty shoot-out to $\mathrm{Y}_{\mathrm{i}}$ kicker -;

- $\mathrm{DP}_{21}$ : - Catch i-th penalty shoot-out strategy to the $\mathrm{Y}_{\mathrm{i}}$ kicker -

Considering the only sequence of 5 shootouts per team we get the decomposition of Table 6 .

Table 6. Second level decomposition of penalty shootouts

\begin{tabular}{|c|c|c|c|c|c|c|c|c|c|c|c|c|}
\hline & & & & & & Gam & e stra & tegy & (DP0) & & & \\
\hline & & & Xi per & nalty & takers & strat & & & goalk & reepe & r stra & egy \\
\hline & & & DP11 & DP12 & DP13 & DP14 & DP15 & DP2 & DP22 & DP23 & DP24 & DP25 \\
\hline \multirow{10}{*}{ 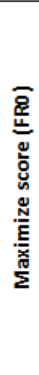 } & \multirow{5}{*}{$\begin{array}{c}\text { Minimize } \Sigma \\
\text { (Failed } \\
\text { shootouts) } \\
\text { (FR1) }\end{array}$} & FR11 & $x$ & & & & & & & & & \\
\hline & & FR12 & & $x$ & & & & & & & & \\
\hline & & FR13 & & & $x$ & & & & & & & \\
\hline & & FR14 & & & & $x$ & & & & & & \\
\hline & & FR15 & & & & & $x$ & & & & & \\
\hline & \multirow{5}{*}{$\begin{array}{c}\text { Maximize } \Sigma \\
\text { (Failed } \\
\text { shootouts by } \\
\text { opponents) } \\
\text { (FR2)) }\end{array}$} & FR21 & & & & & & $x$ & & & & \\
\hline & & FR22 & & & & & & & $x$ & & & \\
\hline & & FR23 & & & & & & & & $x$ & & \\
\hline & & FR24 & & & & & & & & & $x$ & \\
\hline & & FR25 & & & & & & & & & & $x$ \\
\hline
\end{tabular}

This decomposition meets the Axiom of Independence. The strategies adopted by the two teams are axiomatically independent. Players carry out independent choices, not affected by the influence of the previous actions.

\subsection{Third level decomposition}

It is possible to proceed to a successive axiomatic decomposition. The semplification referred to in paragraph 3 will let us state that a kicker has three shooting possibilities in general randomization equilibrium conditions instead of 2 as in restricted randomization. On the other hand, the goalkeeper can dive to his right, stand still in the centre or dive to his left. Furthermore, it is proved that kicker and goalkeeper's actions are statistically independent. [12, 13]. This scenario allows us to decompose each second level functional requirement into further lower level ones. For simplicity reasons, in the next paragraphs only players with a GR-type shooting behaviour will be considered. 


\subsubsection{Third level decomposition from kickers side}

About $\mathrm{X}_{\mathrm{i}}$ kicker's actions there are three possible shooting choices (L, C, R). Each single choice is associated a specific probability to score a goal. The associated probability triad $\left(\mathrm{a}_{11}, \mathrm{a}_{22}, \mathrm{a}_{33}\right)$ has already been estimated in paragraph 3.1. In valid conditions of Nash's equilibrium, the three probabilities are equal. However, in situations where physical and mental stress increases, after 120 minutes of game, some deviations from the standard behavior may arise. However, in ideal conditions or in case of low level of stress, CEME decomposition can be developed as follows for the $\mathrm{X}_{\mathrm{i}}$ player:

- $\mathrm{FM}_{\mathrm{iL}}$ : - $\mathrm{X}_{\mathrm{i}}$ kicker's probability to score a goal to $\mathrm{GY}$ goalkeeper's left: $\mathrm{a}_{11 \mathrm{~L}}-$;

- $\mathrm{FR}_{1 \mathrm{iL}}$ : - Score a goal to the left -;

- $\mathrm{DP}_{1 \mathrm{iL}}$ : - Choice kicking to the left -;

- $\mathrm{FM}_{1 \mathrm{ic}}$ : $-\mathrm{X}_{\mathrm{i}}$ kicker's probability to score a goal in the centre of the goal door: $\mathrm{a}_{11 \mathrm{C}} \mathrm{C}^{-}$;

- $\mathrm{FR}_{1 \mathrm{ic}}$ : - Score a goal in the centre -;

- $\mathrm{DP}_{1 \mathrm{ic}}$ : - Choice kicking to the centre -;

- $\mathrm{FM}_{1 \mathrm{ic}}$ : - Probability for kicker $\mathrm{X}_{\mathrm{i}}$ to score a goal with a

shot to GY goalkeeper's right: $\mathrm{a}_{11 \mathrm{R}}$-;

- $\mathrm{FR}_{1 \mathrm{ic}}$ : - Score a goal in the right -;

- $\mathrm{DP}_{\text {lic: }}$ - Choice kicking to the right -.

\subsubsection{Third level decomposition from goalkeeper side}

GX goalkeeper strategy is also made up of three possible choices (L, C, R). The decomposition that has been introduced considers the overall probabilities to catch or make the opposing kicker fail. This triad of probabilities $\left(b_{11}, b_{22}, b_{33}\right)$ has already been defined mathematically in paragraph 3.2. Ultimately, for each $\mathrm{Y}_{\mathrm{i}}$ opposing player, with $\mathrm{i}=1 \ldots .5$ we can have an estimation of the triad $\left(b_{2 i L}\right.$, $\mathrm{b}_{2 \mathrm{iC}}, \mathrm{b}_{2 \mathrm{iR}}$ ). This estimation represents the probability distribution for GX goalkeeper to catch a penalty shootout to the $Y_{i}$ kicker. Furthermore, for each couple of professional soccer players $\left(\mathrm{GX}\right.$ and $\left.\mathrm{Y}_{\mathrm{i}}\right)$, the specific triads aim to standard values which are representative of Nash's conditions equilibrium theorem. However, in conditions of strong physical and mental stress one can have deviations from the standard behavior. Therefore, shooting or goalkeeper's dive preferences may be observed. The statistics analysis of these preferences allows us to estimate the triad values $\left(\mathrm{b}_{2 \mathrm{iL}}, \mathrm{b}_{2 \mathrm{iC}}, \mathrm{b}_{2 \mathrm{iR}}\right)$ by the end of extra time. Usually, deviations from standard behavior are more common in the penalty takers.

Such considerations lead us to the following decomposition.

- $\mathrm{FM}_{2 \mathrm{iL}}$ : - GX goalkeeper's probability to catch $\mathrm{Y}_{\mathrm{i}}$ kicker's shot, by diving to his left: $\mathrm{b}_{2 \mathrm{iL}}-$;

- $\mathrm{FR}_{2 \mathrm{iL}}$ : - Catch a shot to his own left -;

- $\mathrm{DP}_{2 \mathrm{iL}}$ : - Choice to dive left -;

- $\mathrm{FM}_{2 \mathrm{ic}}$ : - GX goalkeeper's probability to catch a goal by

Yi kicker, standing still in the centre: $b_{2 i c}-$;

- $\mathrm{FR}_{2 \mathrm{ic}}$ : - Catch in the centre -;

- $\mathrm{DP}_{2 \mathrm{ic}}$ : - Choice to stand still in the centre of the goal

door -;
- FM2 $2_{\mathrm{iC}}$ : - GX goalkeeper's probability to catch a goal by Yi kicker, diving to his own right: $b_{2 i R}$-;

- $\mathrm{FR}_{2 \mathrm{iC}}$ : - Catch a goal at his own right -;

- $\mathrm{DP}_{2 \mathrm{ic}}$ : - Choice to dive to the right -.

It is clear that the Independence Axiom is met. The overall matrix is diagonal.

\section{AD CEME methodology application to the penalty shootouts in real cases}

In real cases penalty shootouts are influenced by different variables. Not only physical and mental stress can make diverge kickers' behavior from the standard model previously described. However, the same shooting order can give an advantge to the team scoring first [12, 17]. Also, when you know the shooting behavior of those kickers often take penalty shootouts, we could not have any information about the other opposing kicker's behavior. In this case, the model previously defined might be insufficient for a reliable prediction. Thus, the definition of an overall shooting strategy could be inadequate.

\subsection{The penalty shoot-out game under incomplete information}

The necessary information is not always available to define the shooting behavior of a designated penalty taker. Some players rarely kick the penalty shootouts. For example, by quoting Chiappori's model, this means that there are situations where the goalkeeper ignores if the opposing kicker will adopt GR-type or RR-type strategies. It also means that Nash's equilibrium conditions are not met. The goalkeeper does not know the payoff matrix values associated to the game. Thus, it is not possibile to define solutions in Nash's equilibrium conditions. However, we can turn an incomplete information game into a game of imperfect information $[18,19]$. At the same time, we can find an equilibrium state of the derived game. It is the so-called Bayes's equilibrium. This new equilibrium situation allows us to arise strategies both for kickers and goalkeeper as already done with Nash's equilibrium.

\subsection{Axiomatic decomposition of a penalty shoot-out in Bayesian equilibrium}

If reapplying the criteria of CEME-type $\mathrm{AD}$ methodology the decomposition can be represented by Table 7. $A_{\mathrm{iiRR}}$ and $\mathrm{a}_{\mathrm{iigR}}$ rules of derivation are the same stated in the previous paragraphs. However, equilibrium solutions have completely changed because they are functions of $\vartheta$, which represents goalkeeper's probability to face a RR-type kicker [18]. 
Table 7. Decomposition in Bayesian equilibrium

\begin{tabular}{|c|c|c|c|c|c|c|}
\hline & & \multicolumn{5}{|c|}{ Penalty takers strategies } \\
\hline & \begin{tabular}{|l} 
Possible \\
strategies
\end{tabular} & \begin{tabular}{|l} 
RR \\
penalty \\
taker \\
kicks left
\end{tabular} & \begin{tabular}{|l|} 
RR \\
penalty \\
taker \\
kicksl \\
right \\
\end{tabular} & \begin{tabular}{|l|} 
GR \\
penalty \\
taker \\
kicks left
\end{tabular} & \begin{tabular}{|l|} 
GR \\
penalty \\
taker \\
kicks \\
centre \\
\end{tabular} & \begin{tabular}{|l} 
GR \\
penalty \\
taker \\
kicks right
\end{tabular} \\
\hline \multirow{2}{*}{$\begin{array}{l}\text { Maximize } \\
\text { penalty } \\
\text { shoot-out } \\
\text { in RR } \vartheta\end{array}$} & $\begin{array}{l}\text { Score a } \\
\text { goal left }\end{array}$ & $a_{11 R R}$ & & & & \\
\hline & $\begin{array}{l}\text { Score a } \\
\text { goal right }\end{array}$ & & $a_{22 R R}$ & & & \\
\hline \multirow{3}{*}{ 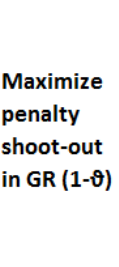 } & $\begin{array}{l}\text { Score a } \\
\text { goal left }\end{array}$ & & & $a_{11 G R}$ & & \\
\hline & $\begin{array}{l}\text { Score a } \\
\text { goal centre }\end{array}$ & & & & $a_{22 G R}$ & \\
\hline & \begin{tabular}{|l} 
Score a \\
goal right
\end{tabular} & & & & & $a_{33 G R}$ \\
\hline
\end{tabular}

Differently from previous situations in Nash's equilibrium, Coloma [18] has already shown that in Bayesian equilibrium:

- Players of both game typologies have a higher probability of success than in Nash's equilibrium conditions;

- Goalkeeper, instead, has a much lower probability of intercepting the goal.

This theoretical result is in line with the empirical evidence that, during penalty shootouts, many penalty takers have failed. For them, goalkeepers are perfectly aware of their shooting behavior. Furthermore, before play-offs, coaches make kickers try shooting tests to simulate the opponents' behavior.

\subsection{The impact of physical and mental stress in the penalty shootouts}

Game theory suggests that both kicker and goalkeeper 's strategical choice they prefer is leave it to probability, putting the opponent in utter uncertainty regarding his own real intentions. A study conducted by Palacios Huerta [17] has demonstrated that professional soccer players adopt random strategies. The result is quite surprising because the idea has already been that psychological mechanisms anticipating his opponent's moves could play a greater role. It should be noted in this respect that soccer players' behavior is true in longterm observations and in normal physical and mental stress conditions. About the penalty shootouts in extra time the situation is much more complicated. In this case, you may observe clear deviations from the standard behavior [20-23].

\subsection{Pursuit effect}

Physical and mental stress may impair the strategy to be adopted. It was verified that who first starts kicking the penalty shootouts has a rate close to $60 \%$ to prevail over the opposing team $[12,17]$. Kicking a penalty shoot-out first, entails a significant psychological advantage. The opposing penalty taker is obliged to "pursuit" [17]. For this reason, UEFA has been considering the reform on the penalty shootouts. The penalty shootouts sequence should change from alternate according to ABABABABAB sequence into the following ABBAABBAAB sequence shortly. This new rule should limit the pursuit phenomenon.

\subsubsection{Axiomatic representation of the pursuit effect}

Pursuit phenomena in the penalty shootouts can be modelled by means of Markov chains. In this case, the result of i-th kicker's penalty shoot-out will depend on $j$ th kicker opposing team's result, which immediately preceded it. However, it can also be formalized in terms of axiomatic decomposition. If we restrict our analysis to the second level decomposition it is easiest to see that, in the series of ABABABAB-type penalty shootouts, the team kicking first has an advantage over the opponents (Fig. 4). At least the first shoot-out is free from any influence. At this point, we are considering the following assumptions:

- There may be influences among successive penalty takers not belonging to the same team;

- There are no influences among successive penalty shootouts for kickers of the same team;

- The influences are limited at the very most to the immediately following shoot-out.

In this scenario, shootouts ABBAABBAA-type will have the same features of Figure 4, such as:

- No matter the team kicking first, the number of influences, detectable at most, is identical for both teams. In this specific case they are two;

- In terms of axiomatic decomposition the number of potential functional coupled requirements is reduced from four to two.

Both representations are not acceptable in terms of $\mathrm{AD}$. This is obvious because such representations do not take account the variables leading to the deviation from the standard model. In real life, pursuit phenomenon could be considered in statistics methods on the basis of data acquired in DataBase HNCR-type. These methods would take into consideration the main physical and mental stress variables of each single kicker under stress conditions. There would be a new functional decomposition also including these new variables, in this way. So, the decomposition would return to be decoupled. 


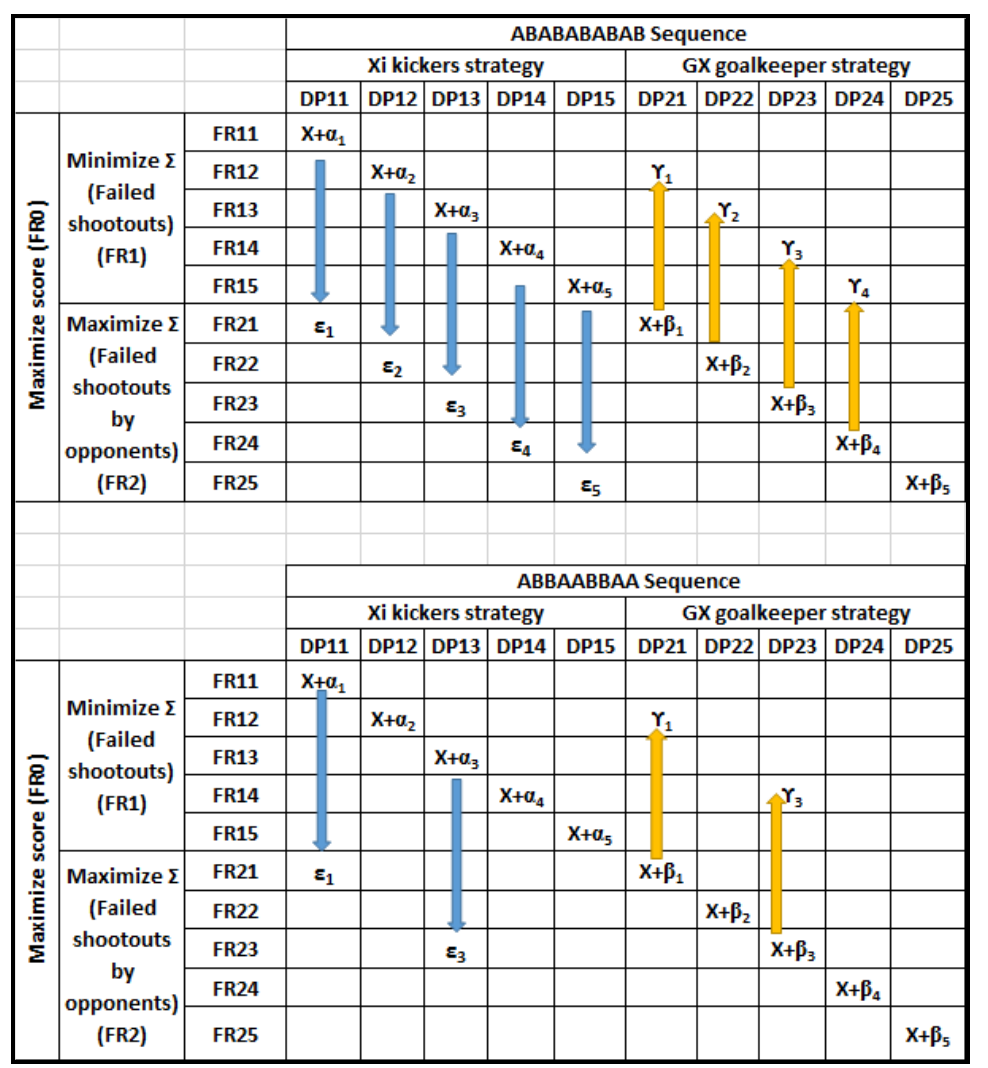

Fig. 4. Pursuit effect

\subsubsection{Functional decoupling}

Previous paragraph has pointed out that in real game conditions several factors need to be taken into account. The main effect of these factors is to diverge the shooting behavior from the standard model. The design matrix is coupled. So that the game representation could not meet the Independence Axiom. In order to overcome this obstacle one has two possibilities:

- Make sure constraints on shooting strategies among opposing kickers are null;

- Estimate the deviations from the standard behavior of soccer players through detailed observations, tests and finally report the statistics in a HCRN-type DataBase.

Situation 1 would be worthy, but in conditions of real game is difficult to guarantee it. Situation 2, instead, may be simulated during the match preparation phase. Necessary data can be acquired by specific consultancies and during trainings by monitoring soccer players' physical and mental condition. At this stage, regression functions, allow us to start an estimation of the parameters of our interest. On the basis of these estimates is possible to build accurate models simulating soccer players' behavior during particular physical and mental stress conditions. At $\S 3.5$ we have defined Lionel Messi's behavior model under physical and mental constraint in this regard. Such deduction has been made possible due to a great volume of easily accessible data about the Argentinian top player. This way, we may decouple the model variables, by asserting the Independence Axiom. Figure 5 in the attached page shows this kind of decomposition for a series of 2 ABAB-type alternate penalty shootouts.

\subsubsection{Typing}

The conducted functional decoupling, as stated in the previous paragraphs, is reflected in the definition of a finite series of predefined behavior types for penalty takers. This means that in a worst-case scenario the goalkeeper could ignore which shooting behavior the opposing kicker will have. Therefore, also in this case, we turn a complex game with incomplete information into a set of simpler games with imperfect information. So, it is possible to identify some game strategies in Bayesian equilibrium. In fact, this situation is the generalization of a specific case concerning the comparison between a goalkeeper and a kicker, whom kicker's shooting behavior is not clear if it is a RR-type or a GR-type.

\subsubsection{Definition of an axiomatic model by Lionel Messi's shootouts in penalties}

Theoretical definitions of the previous paragraphs allow us to define a mathematical model simulating the real shooting behavior by Lionel Messi during penalties shootouts. Let us premise, however, that for simplicity we have neglected the functional decoupling of the pursuit effect. The purpose of this discussion is to try to build a realistic model of Lionel Messi's shooting behavior simulation. This will happen by putting together his two main behaviors. As already described in $\S 3.5$, Messi behaves a GR-type shooting way in normal physical and mental conditions. However, during situations of particular stress, he tends to divert his

Corresponding author: f.rolli@unimarconi.it 
behavior into a Nash's non-equilibrium RR-type shooting model. Thus, shooting preferences of the last model show different success rate. Starting from these two divergent behaviors we can set a mathematical model which includes both cases. The overall model can be built up by using once again the Bayesian equilibrium theory. In this case, at the moment of penalty shootouts in extra time, we can assign a probability $\beta$ when Messi is under stressed conditions. This will lead us to state that by probability $\beta$ his shooting behavior will be Nash's non-equilibrium RR-type. On the contrary, by probability (1- $\beta$ ) when his mental and physical conditions seem to be normal. Watching some videos, you might state that in normal conditions Messi is not influenced by any external events. He is blessed by an amazing concentration. In this case the pursuit effect of penalty shootouts is practically nil for him. On the contrary, we might suppose that under particular stress conditions, besides the deviation from the standard behavior, the player may be leant on by the consequences of the pursuit phenomenon. Regarding Messi, this phenomenon can be defined with the introduction of the disruption $\varepsilon$ into Nash's nonequilibrium RR model. $\varepsilon$ disruption may accentuate the distortion of such model, by restricting Messi's preferred shooting S1 or S2 areas ( $\S 3.5 .3)$. This means that the pursuit effect can increase the asymmetry between S1 and S2. Such situation could make the opponent goalkeeper's intervention easier. Table 8 illustrates the overall model by Lionel Messi' penalty shootouts in extra time.

Table 8. Lionel Messi strategies in penalty shoot-outs

\begin{tabular}{|c|c|c|c|c|c|c|}
\hline & & \multicolumn{5}{|c|}{ Lionel Messi strategies } \\
\hline & $\begin{array}{l}\text { Possible } \\
\text { strategie } \\
s\end{array}$ & $\begin{array}{l}\text { Messi kicks } \\
\text { left }\end{array}$ & $\begin{array}{l}\text { Messi kicks } \\
\text { right }\end{array}$ & $\begin{array}{l}\text { Messi kicks } \\
\text { left }\end{array}$ & $\begin{array}{l}\text { Messi kicks } \\
\text { centre }\end{array}$ & $\begin{array}{l}\text { Messi kicks } \\
\text { right }\end{array}$ \\
\hline \multirow{2}{*}{$\begin{array}{l}\text { Maximize } \\
\text { penalty } \\
\text { shoot-out } \\
\text { in RR } \beta\end{array}$} & $\begin{array}{l}\text { Score a } \\
\text { goal left }\end{array}$ & $a_{11 M R R}-\varepsilon$ & & & & \\
\hline & \begin{tabular}{|l|} 
Score a \\
goal \\
right \\
\end{tabular} & & $a_{22 M R R}+\varepsilon$ & & & \\
\hline \multirow{3}{*}{$\begin{array}{l}\text { Maximize } \\
\text { penalty } \\
\text { shoot-out } \\
\text { in GR (1- } \\
\beta)\end{array}$} & $\begin{array}{l}\text { Score a } \\
\text { goal left }\end{array}$ & & & $a_{11 M G R}$ & & \\
\hline & \begin{tabular}{|l|} 
Score a \\
goal \\
centre \\
\end{tabular} & & & & $a_{22 M G R}$ & \\
\hline & $\begin{array}{l}\text { Score a } \\
\text { goal } \\
\text { right }\end{array}$ & & & & & $a_{33 M G R}$ \\
\hline
\end{tabular}

\subsection{Utility}

Kickers shooting modalities's typing in conditions of physical and mental stress allow us to define a powerful mechanism of penalty shootouts simulation. This mechanism is dynamic. It can be used to prepare for an identification algorithm of the penalty shootouts takers. It can also make it possible to determine the order by which the penalty takers must show by the opposing goalkeeper. It is then possible to simulate the probable opponents' shooting order with the axiomatic decomposition mechanism. Therefore, a series of soccer players minimizing the pursuit effect could be drawn. As regards goalkeeper, his thorough knowledge of the opponents behaviors, gives him a considerable advantage. Indeed, for a few years now, professional clubs have access to data, statistics and simulations made available by specific consultancies. In this respect, during the 2016 European Championship the German national team made use of shootouts simulations created by a famous IT company. Such simulations were developed by means of an accurate Big Data analysis in soccer. As a result, the German national team finally beated the Italian national team in shootouts. An extraordinary event given that the Italian team always historically predominated in the official matches between the two teams. However, the final victory of the match will get to the Portuguese national team.

\section{Conclusions}

Game theory is difficult to apply in particularly complex contexts. CEME methodology provides a powerful modeling tool. This derives from the common axiomatic basis of the two analytical approaches. For this reason, we can say that the main benefit that CEME can provide to Game Theory is to facilitate the decomposition of a complex zero-sum game into further elementary games, by preserving at the same time the intrinsic features of the primary one. This contributes to represent a minimax problem into a simple axiomatic decomposition of elementary actions. Thus, Independence Axiom allows to decrease the elementary actions into a minimum set exhaustively representing the whole game. Each single elementary action so decomposed is mutually independent from the others. Therefore, it is possible to act on every one of them, by modifying the related strategy. However, the Information Axiom application leads us to identify the strategies in Nash's equilibrium, if the game is with incomplete information or with solutions in Bayesian equilibrium. Both equilibrium typologies allow us to associate to each specific elementary action a measure which represents the probability of success for whom shall put it in place. This way, we can predefine a management of penalty shootouts in extra time during play-offs which allows us to:

- Define an overall strategy of penalty takers selection; - Put the same players in order, along a predefined sequence minimizing the pursuit effect. This way, players with deviations from minor standard behavior will be chosen to kick the penalty shoot-out after the first one kicked by the opposing team and for the last, big shot;

- Arrange for a goalkeeper's strategy based on well known features of opposing kickers' shootouts.

\section{References}

1. S. Kuper, S. Szymanski, Soccernomics: Why England Loses, Why Spain, Germany, and 
Brazil Win, and Why the US, Japan, Australia and Even Iraq - Are Destined to Become the Kings of the World's Most Popular Sport, Nation Books, (2014);

2. G. Arcidiacono, K. Yang, J. Trewn, L. Bucciarelli, Application of Axiomatic Design for Project-Based Learning Methodology, Procedia CIRP, Vol. 53, pp. 166-172, (2016);

3. G. Arcidiacono, D.T. Matt, E. Rauch, Axiomatic Design of a Framework for the Comprehensive Optimization of Patient Flows in Hospitals, Journal of Healthcare Engineering, Article number 2309265, (2017);

4. R. Henley, C.A. Brown, Axiomatic Design Applied to Play Calling in American Soccer, Proc. CIRP 53, 206-212 (2016);

5. C.A. Brown, Decomposition and Prioritization in Engineering Design, Proceedings ICAD2011 (2011);

6. C. Cavallini, A. Giorgetti, P. Citti, A. Meneghin, Sviluppo di un approccio olistico per l'analisi e la risoluzione delle non conformità, AISS, 3, 1 (2012);

7. F. Rolli, A. Giorgetti, P. Citti, Integration of Holistic Non-Conformities Management and Axiomatic Design: a case study in Italian Income Tax Returns Management, Proc. CIRP 34, 256-262 (2015);

8. F. Rolli, A. Giorgetti, P. Citti, M. Rinaldi, Improvement of the compilation process of the Italian income certifications: a methodology based on the evaluation of the information content (Part 1), Proc. CIRP 53, 56-62 (2016);

9. A. Giorgetti, C. Cavallini, A. Ciappi, G. Arcidiacono and P. Citti, A holistic model for the proactive reduction of non-conformities within new industrial technologies, IJMERR, 6 , 4 (2017);

10. A. Giorgetti, G. Arcidiacono, A. Ciappi, R. Barbieri, and P. Citti, HNCR model following robust approach, QREI (2018);

11. J. Von Neumann, O. Morgenstern, Theory of Games and Economic Behavior, Princeton University Press, (1944);

12. I. Palacios-Huerta, Professionals Play Minimax, Review of Economic Studies 70, 395-415 (2003);

13. PA. Chiappori, S. Levitt, Steven and T. Groseclose, Testing Mixed-Strategy Equilibria when Players are Heterogeneous: The Case of Penalty Kicks in Soccer, American Economic Review, 92,1138-1151 (2002);

14. J. Nash, Non-Cooperative Games, Annals of Mathematics, 54, pp 286-295 (1951);

15. G. Coloma, Penalty Kicks in Soccer: An Alternative Methodology for Testing MixedStrategy Equilibria, Journal of Sports Economics, 8, 530-545, (2007);

16. G. Jordet, E. Hartman, C. Visscher \& K. A. P. M. Lemmink, Kicks from the penalty mark in soccer: The roles of stress, skill, and fatigue for kick outcomes, Centre for Human Movement Sciences, University of Groningen, University Medical Centre, Groningen, The Netherlands Published online (2007);

17. I. Palacios-Huerta, Beautiful Game Theory. How Soccer Can Help Economics, Princeton University Press, (2016);

18. G. Coloma, The Penalty-Kick Game under Incomplete Information, Serie Documentos de Trabajo, Universidad del CEMA: Área: economía, 487, (2012);

19. J. Harsanyi, Games with Incomplete Information Played by Bayesian Players, Management Science, 14, 159-182, (1967);

20. W. Schwarz, Compensating tendencies in penalty kick decisions of referees in professional football: Evidence from the German Bundesliga 1963-2006, Journal of Sports Sciences, 29(5), 441-447, (2011);

21. N. Anbarci, S. Ching-Jen, M. Utku Unver, Fair Tiebreak Mechanisms: The Case of FIFA Penalty Shootouts, SSRN Electronic Journal, 1, (2015);

22. T. P. Vandebroek, B.T. McCann, G. Vroom, Modeling the Effects of Psychological Pressure on First-Mover Advantage in Competitive Interactions: The Case of Penalty Shoot-Outs, Journal of Sports Economics, 19(5), 725-754, (2016);

23. M. Bar-Eli, O. Azar, I. Ritov, Y. Keidar-Levin, G. Schein, Action Bias Among Elite Soccer Goalkeepers: The Case of Penalty Kicks, Journal of Economic Psychology, 28, 606-621, (2007). 


\begin{tabular}{|c|c|c|c|c|c|c|c|c|c|c|c|c|c|c|}
\hline & & & & \multicolumn{11}{|c|}{ ABABABABAB Sequence } \\
\hline & & & & \multicolumn{5}{|c|}{ Xi penalty takers strategy } & \multicolumn{6}{|c|}{ GX goalkeeper strategy } \\
\hline & & & & DP11 & DP11 $\beta$ & DP12 & DP12 $\beta$ & DP12Y & DP21X & DP21a & DP21E & DP22X & DP21 $\alpha$ & DP21 $\varepsilon$ \\
\hline \multirow{11}{*}{ 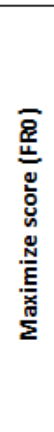 } & \multirow{5}{*}{$\begin{array}{c}\text { Minimize } \Sigma \\
\text { (Failed } \\
\text { shootouts) } \\
\text { (FR1) }\end{array}$} & \multirow{2}{*}{ FR11 } & FR11X & $x$ & & & & & & & & & & \\
\hline & & & FR11 $\beta$ & & $\beta_{1}$ & & & & & & & & & \\
\hline & & \multirow{3}{*}{ FR12 } & FR11X & & & $\mathrm{x}$ & & & & & & & & \\
\hline & & & FR11 $\beta$ & & & & $\beta_{2}$ & & & & & & & \\
\hline & & & FR11Y & & & & & $\gamma_{2}$ & & & & & & \\
\hline & \multirow{6}{*}{$\begin{array}{c}\text { Maximize } \Sigma \\
\text { (Failed } \\
\text { shootouts } \\
\text { by } \\
\text { opponents) } \\
\text { (FR2) }\end{array}$} & \multirow{3}{*}{ FR21 } & FR21X & & & & & & $x$ & & & & & \\
\hline & & & FR11 $\alpha$ & & & & & & & $\alpha_{1}$ & & & & \\
\hline & & & FR11ع & & & & & & & & $\varepsilon_{1}$ & & & \\
\hline & & \multirow{3}{*}{ FR22 } & FR21X & & & & & & & & & $\mathrm{x}$ & & \\
\hline & & & FR11 $\alpha$ & & & & & & & & & & $\alpha_{2}$ & \\
\hline & & & FR11E & & & & & & & & & & & $\varepsilon_{2}$ \\
\hline
\end{tabular}

Fig. 5. Functional decoupling for a series of 2 ABAB-type alternate shootouts 